\title{
Images of Person-Organization Fit: Elements Affecting Employee Organizational Behavior
}

\author{
Ilona Swiatek Barylska \\ Faculty of Management, University of Lodz, Poland \\ swiatek@uni.lodz.pl
}

\begin{abstract}
The purpose of the paper is to build upon the existing literature a new approach to personorganization fit, in particular, employees' perception of the $P$-O fit, taking into consideration two main criteria: 1) the level of formalization as a company's characteristics and 2) an employee's certainty orientation as a person's characteristics. The congruence between the situational factor (level of formalization) and personal traits (certainty orientation) influence individual organizational behavior. A two-dimension model illustrated by a four-element matrix is created by the author to present the concept and describe employees' organizational behaviors. There are four images of P-O fit developed in the paper: 1) a kayak on a stormy ocean 2) ferries on a lake, 3) a cruise ship in a pond and 4) yacht on friendly seas.
\end{abstract}

Keywords: Certainty Orientation, Formalization, Images of Organization, Organizational Behavior, Person-Organization Fit

\section{Introduction}

The company ceases to be a place where the employee is mainly provided with funds for life. It is a place where employees look for development opportunities and challenges - a place where they want to feel good. Work is no longer the meaning of life. The organizational world is described by changing paradigms and organizational models which are the consequences of the new environment, new characteristics of the employees and a new person-organization relationship (Laloux, 2014; SwiatekBarylska, 2013). The change of employees' place in the organization is, like most organizational processes, a complex phenomenon, caused by a number of interrelated factors. One of them is the recognition of knowledge as the fourth, most important factor of production (Toffler, 1980). In consequence, one can observe a move away from building a competitive advantage on the basis of material resources towards a social capital (Becker, 1970). This transformation fundamentally changes the role of 
employees in the management process. In a society of knowledge, employees have much more to offer than their availability or physical strength. They offer the company not only their time and skills, but also, and perhaps above all, intellectual capital (Czarnecki, 2011). Organizations are dominated by “wise employees performing tasks wisely", which requires managers' greater sensitivity than if they were simply managing traditional, formalized factories (Handy, 2002). Although still used in some companies, management's focus on the allocation of resources, the dominance of economic incentives, strict control of the job, and shaping of the organizational structure in which there is a clear division of power, is systematically being replaced by solutions which lead to collaboration, commitment and knowledge sharing.

There is a tendency in management to move from distributive justice to procedural justice, from a transactional approach to employee relationship based management. Distributive justice is connected with the psychological mechanism that lies in the fact that employees receive a salary which they think they deserve (fair), thus they feel satisfied and reciprocate the fulfillment of obligations to the company. Procedural justice is associated with the activation of another mechanism. Its starting point is employers' fair approach to employees. It helps to build confidence and trust, which in turn becomes the basis of voluntary cooperation. Employees whose activity is voluntary go beyond the scope of their duties, they are creative and they share their knowledge (Chan \&Mauborgne, 2006). To achieve such results, person-organization fit is a necessary condition. As person-organization fit is a special kind of relationship between two partners, one should be aware that the perception of this relationship depends on the perspective of the analysis. It can be perceived differently by the employee and by the company.

Person-organization fit is not an element of a formal job contract but can be treated as an element of a psychological contract (Wellin, 2007). It does not have a written form but its meaning is very important. The analysis of variables that moderate the personorganization fit is the subject of research conducted mainly by psychologists (e.g. Guan et al., 2011) but its importance is increasing among management specialists and scientists (e.g. Westerman \& Cyr, 2004). Empirical research has uncovered various 
moderators between P-O fit but some important aspects remain unexamined. Personorganization fit influences individual organizational behavior. The paper concentrates on two elements which shape employee organizational behavior as a result of P-O fit: the level of organizational formalization as a situational factor, and employee's certainty orientation as an individual factor in the context of person-organization fit.

\section{Literature Review}

\subsection{Person-Organization Fit}

There is a variety of definitions of person-organization fit. Generally speaking, one can say that fit means the situation when at least two elements match. At the end of the $20^{\text {th }}$ century, on the basis of a literature review, Kristof defined personorganization fit as the compatibility between people and organizations that occurs when (a) at least one entity provides what the other needs, or (b) they share similar fundamental characteristics, or (c) both (Kristof, 1996). This definition integrates fit theories which were also described by Muchinsky and Monahan (Muchinsky \& Monahan, 1987). They noticed the duality of understanding person-organization fit: supplementary and complementary fit. Supplementary fit has been conceptualized as the similarity of characteristics between an employee and the work environment (organization) i.e. the congruence of goals and values. Complementary fit exists when one entity possesses characteristics that the other wants or needs e.g. the company hires the manager who possesses a human resource experience that the company currently lacks (Guan et al., 2011). Other authors make a distinction between the demands-abilities fit and the needs-supplies fit (Edwards, 1996). The former occurs when an individual has the abilities required to meet the demands of the organization. It is described from the organizational perspective. The abilities in this case mean any competences the employee possesses to meet organizational demand/expectations e.g. crisis management.

The needs-supplies fit attitude concentrates on the employee's needs and the capability of the organization to fulfill those needs, e.g. employee needs a safe work environment (certainty oriented person) and the organization provides the employee with a long-term contract (Arbour et al., 2014). Person-organization fit is important 
due to it is commonly expected and positive consequences, both for the employees and for the organizations, as verified in research. Researches show that when employees' values match those of the organization, greater job satisfaction, work commitment, and job choice can be obtained (Han et al, 2015; Kristof-Brown et al., 2005; Oh et al., 2014; Swider, Zimmerman, \& Barrick, 2015). Researchers have also proposed that contextual differences in working environments and individual differences among employees may serve as boundary conditions for these relations (Jansen \& Kristof-Brown, 2006). There can be many perspectives taken into account to analyze such a complex phenomenon as person-organization fit. This paper concentrates on supplementary fit. It means the congruence of organizational and individual characteristics. From the variety of characteristics, two important ones were chosen: formalization as a characteristic of an organization and certainty orientation as an individual characteristic. Both elements affect employees' behavior in the organization and crate different results.

\subsection{Determinants of Individual Behavior in Organization}

The scientific discussion about the determinants of human behavior has for years been focused on the question of what is a dominant group of factors which determines employees' behavior. The traditional psychology of personality perceived behavior as a function of personal attributes (traits, emotions, attitudes, motives and values). Allport in his book Personality: A Psychological Interpretation (Allport, 1937) echoed the Doctrine of Traits with the following words: In everyday life, no one, not even a psychologist, doubts that underlying the conduct of a mature person there are characteristic dispositions or traits.

Traditional social psychology, by contrast, construed behavior as a function of the environment. The Doctrine of Traits and the Doctrine of Situationism had an impact on the trait-situation debate. At the beginning, they were treated as two independent factors until the 1930s when both approaches were integrated by Kurt Lewin (Kihlstrom, 2013). He expressed this idea in an equation: $B=f(P, E)$. It is not a mathematical formula but a general idea about the determinants of behavior. In this equation, the person $(\mathrm{P})$ and his environment $(\mathrm{E})$ have to be viewed as variables which 
are mutually dependent upon each other. In other words, to understand or predict behavior the person and the environment have to be considered as one constellation of interdependent factors. We call the totality of these factors the life space (Lewin 1946/1951). The next step in the person-situation research was the Doctrine of Interactionism formulated by Bowers. According to this doctrine, we cannot talk about the primacy of either the traits or the situation as determinants of individual behavior in an organization. Interactionism argues that situations are as much a function of the person as the person's behavior is a function of the situation (Bowers, 1973). Using Lewin's formula, it can be described in the following equation: $B=f(P$ $\mathrm{x} E$ ), where personal and environmental factors are multiplicative, i.e. the person (P) and the environment (E) both affect the behavior (B), but the effect of each variable depends on the level of the other. The effect of the personality depends on the environment (the situation the person is in), and the effect of the environment (situation) depends on the person who is in it.

\subsection{Level of Formalization as an Element of Situation}

Formalization is defined as the degree to which rules and procedures are followed by an organization and its employees in carrying out different activities (Rai, 1983). The essence of formalization is to limit the freedom of activities in the organization by imposing written standards on the tasks and ways they are implemented. Formalization allows an organization to raise the predictability of employees'

behavior, standardize and coordinate it. Formal rules determine how to act in a particular situation and, thus, partly program the behaviors. Bureaucratic organizations are characterized by: a well- defined hierarchy of authority, formal rules and procedures, a clear division of labor, with parts of a complex job being handled by specialists, impersonality, without reference or connection to a particular person and careers based on merit.

It is important to achieve the right level of formalization. Over-formalization (too a high level) involving the validity of too many, too detailed and (or) too stringent regulations, does not allow for flexibility. Under-formalization (too low a level) leads to a situation where employees have too much freedom in the choice of tasks and how 
they are implemented, and often make the wrong choices. This can cause a lack of internal coordination and disorientation of participants. The level of formalization is measured by: 1) the number of regulations which define goals and objectives and how they are implemented, 2) the level of regulation detail and 3) the degree of stringency of regulations and the severity of the sanctions threatened in the event of failure to comply with the regulations (Kozminski \& Piotrowski, 1995). The high dynamics of events inside an organization and its environment requires non-routine behavior. Striving for high formalization of the organization, giving rise to Max Weber's concept, is not applicable in contemporary organizations. A high level of formalization works well in a stable environment and routine situations - in organizations in which tasks are explicit and certain.

Creating more detailed regulations, and raising the level of bureaucracy, leads to a restriction of the freedom of participants in the organization, and the organization becomes unable to implement adaptive changes (Crozier, 2010). Orientation to a high level of formalization may become an obstacle to making changes which are necessary to adapt the organization to new circumstances and the requirements of the environment. Another negative effect of excessive formalization is the high level of monitoring the compliance of regulations. Formalization can also lead to incongruous behaviors and situations when employees do not behave rationally but as guardians of procedures. This reduces the rationality and efficiency of the company (Bielski, 1992). The negative consequences of a high level of formalization can also be observed in the social sphere of an organization. It degrades the employee as an active and creative participant in organizational processes. By contrast, low formalization directly and negatively influences knowledge transformation to systemic procedures and database (Girdauskiene \& Savaneviciene, 2012).

Lack of autonomy and independence of action can cause frustration among some employees, or passive submission to the formal rules. On the other hand, some employees feel comfortable in a formalized organization. They know what to do and how to do their job. They do not have to solve problems or take responsibility. The purpose of formalization is to give order to chaos. Rules and procedures are 
implemented to standardize the action of the organization's members. If they do not know what their duty is or how to do their job, formalization is very helpful. As today's business world is very complicated, the number of rules and the level of formalization increase dramatically and create a vicious circle of bureaucracy. It can also be a threat to individual freedoms, with the ongoing bureaucratization leading to a "polar night of icy darkness." Formalization can hamper worker creativity and interfere with professional judgment, which decreases motivation and satisfaction.

\subsection{Employee Certainty Orientation as an Individual Trait}

Coping with uncertainty is an important aspect for individual organizational behavior. Certainty- versus uncertainty-oriented employees have different expectations from their organization, exhibit differentiated behavior (Sorrentino et al, 1995), and have different cognitive processes. Uncertainty orientation is a self-regulatory style that focuses on how one approaches and handles uncertainty (Sorrentino \& Roney, 2000). Individuals exist on a bipolar continuum, from those who are certainty-oriented (CO) to those who are uncertainty-oriented (UO). The reduction of uncertainty is the fundamental reason (apart from the need for achievements and affiliation) directing employees' activities. People have different ways of responding to situations of uncertainty. Those who are uncertainty-oriented see such situations as a challenge, and those with a low level of tolerance to uncertainty treat it as a threat. For uncertainty-oriented employees, the preferred method of dealing with it is to seek out information and engage in an activity that will directly resolve the uncertainty. They try to understand and discover aspects of the environment about which they are uncertain. They are especially engaged by new information about the self and the environment and the prospects of learning from such a situation (e.g. Roney \& Sorrentino, 1995). Such people can be described as having a strong "need to know." Certainty-oriented ones develop a self-regulatory style that circumvents uncertainty. When given a choice, they undertake activities that maintain clarity, and when confronted with uncertainty they rely on others or heuristic devices such as leadership status, group norms or source expertise instead of on more direct methods of resolving uncertainty (Sorretino et al., 2005). 


\section{Methodology}

Person-organization fit may be described using different criteria. Theoretical model of person-organization relationship which is presented below refers to two characteristics important for contemporary organizations. The level of formalization is treated as a characteristic describing the organization and at the same time the employees' environment. Certainty orientation is used as an employees' characteristic. Different forms of person-organization fit are described by the author of the paper using analogies/images that are very helpful in describing the organizational world (Morgan, 2006). The first criterion, formalization of the organization, can be described as a place located on the axis between two opposite ends of a continuum, two model states of an environment: a high level of formalization and a lack of formalization. A lack of formalization means a minimal number of procedures and control, meaning that the company is managed by values not by formalization. On the basis of the second criterion, employees are divided into two "ideal" types: (1) certainty-oriented, and (2) uncertainty-oriented. There is a continuum between two types. Taking into consideration these two criteria, one can define four types of person-organization fit (see figure 1).

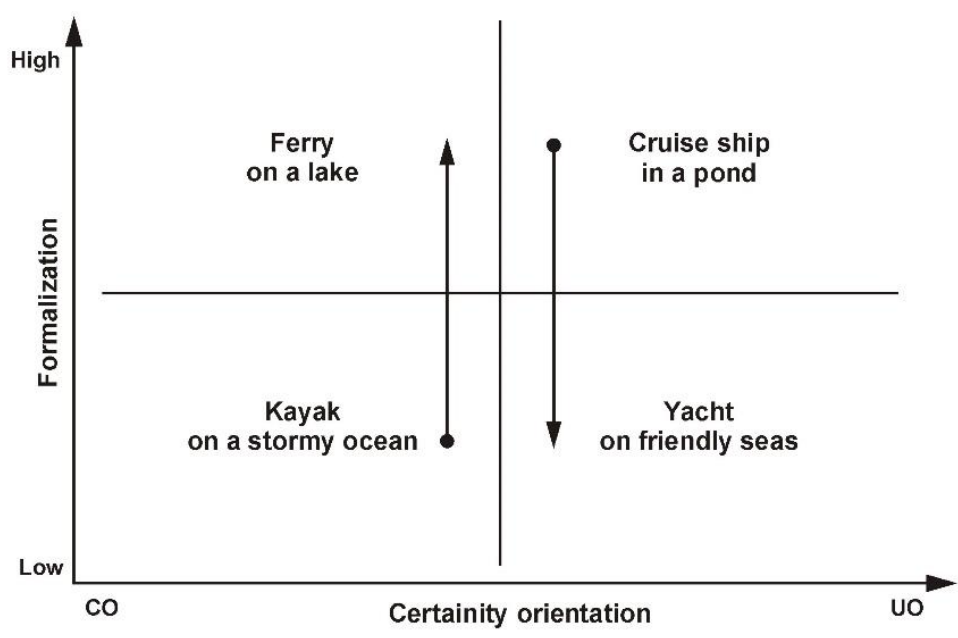

Fig 01: Images of person-organization fit

Source: Author Constructed, 2016

$\mathrm{UO}$ - Uncertainty Oriented Employees

$\mathrm{CO}-$ Certainty Oriented Employees 
The organization characteristic (formalization) is presented on the vertical axis. The horizontal axis presents employees' certainty orientation. The lower-left quadrant can be described as a kayak on a stormy ocean. Certainty oriented employees work in a non-formalized organization. This is a situation with a lack of person-organization fit. Working in such an environment is uncomfortable for employees. They feel lost, disoriented and very nervous in a non-formalized organization. Modern organizational structures without strictly defined power centers and hierarchy of authority cause confusion, as this type of employee needs a clear structure. A low number of formal rules and procedures demand that they must gather information, solve problems and implement the solutions but they are unsure about what to do and how to do it. They often have to ask for help, either from supervisors or co-workers. In consequence, they can be perceived by the manager as dependent employees who need additional support and care.

Team members quickly realize that their colleague is afraid of making decisions so usually delays it, and tasks are not always done because the employee is afraid of doing their job in an unclear situation. The employee needs a lot of detailed instructions, which is time consuming. Generally, he/she doesn't fit the team. The psychological costs of the misfit are high for the employee. From a managerial point of view, this situation is also not effective because the management method used is not appropriate for this type of employee. As this situation is named a stormy ocean, an employee can be compared to castaway in a kayak. The second quadrant is the upper-left one. It is named ferry on a lake. Certainty-oriented employees work in a highly formalized organization. There is an alignment between organization and personal characteristics. The comparison of the organization to the lake give an image of an environment that is stable, and easy to observe and predict. In this environment employees feel comfortable.

The organizational structure and hierarchy are well defended. All the duties and methods are set out so employees' behavior is solid and standardized. Employees' behavior is a reaction to the rules and procedures. The duties are mostly repetitive and do not demand creativity. Employees appreciate the stability. It is important for them. 
The managers use an autocratic management style as the most effective ones with certainty oriented employees. A career path is well defined and based on merit. As the company is compared to a lake, the image of the employees can be compared to a ferry which regularly travels from port to port according to timetables and maritime laws. A storm occurs occasionally but in this situation there is a general order not to sail due to dangerous weather conditions. The upper right quadrant image is called cruise ship in the pond.

Uncertainty-oriented employees work in a formalized environment. They are disappointed because the rules and instructions stop their creativity and initiatives. It decreases the intrinsic motivation and commitment. They analyze the situation, have ideas for improvements or changes, and invent new ways of doing the job, but it is not expected by the managers. This type of employee is not very respectful of procedures and organizational structure. They are ready to ignore the rules to achieve their goal. This kind of behavior is not accepted in a formalized organization. Managers are afraid of this type of employee for two reasons: 1) they destroy team spirit and impede achieving the goals, and 2) they treat them as rivals for their managerial position.

The co-workers do not accept the "strangers" who undermine the stable elements of organizational life. It is against the organizational culture. Although the employees are doing their best to improve the organization, the results of their performance appraisal are rather poor. The situation of working in a formalized company is frustrating for uncertainty-oriented employees. They perceive their situation as being modern ship which is to sail in a small area of water. Employees leave this type of company as soon as possible. The situation in the lower-right quadrant is called yacht on friendly seas.

Uncertainty-oriented employees work in not formalized organization. This is a situation of person-organization fit. Employees who value independence, are creative, and open to changes feel very comfortable in not formalized organization. The company is a space which is friendly to the employees, who have the possibility to use and develop their competencies. The job is not standardized and employees do not 
have to follow formal rules and procedures. As they are uncertainty-oriented, it is motivating and increases employees' engagement. Managers appreciate their employees' openness to change and development. They are ready to delegate to them variety of tasks and are not obliged to control them if the subordinates follow the rules. Managers are more like counselors than controllers. This type of employee supports company flexibility.

They are not afraid of changes and do not treat their company as a place where they have to spend the rest of their life. It is more a place where they want to stay. The situation can be compared to a sailor who is sailing on a well-equipped yacht on friendly seas. Two quadrants, lake and friendly seas represent matched situations for certainty and uncertainty-oriented employees, respectively. These are model situations of good person-organization fit. These situations are very comfortable for employees and beneficial for the company. The following two types of behaviors, stormy ocean and pond, are the result of incompatibility between the person and organization.

Employees do not feel comfortable in this working environment and they try either to adapt to the organization, which is very difficult in the long run, or look for a new job. The natural direction of the shift is presented on the figure as two arrows. One direction, preferred by certainty-oriented people, is a shift from the stormy ocean (not formalized company) towards to the lake (formalized company). The second direction, popular among uncertainty oriented employees, is a shift from the pond (formalized company) to the friendly seas (not formalized company). When the uncertainty of the situation does not match one's uncertainty orientation (i.e., an unmatched situation), people become disengaged from the situation (Sorrentino et. al. 2009).

\section{Conclusion}

As the literature review points out, the person-organization fit is a phenomenon which is important for both parties of this relationship. It is important from the employee's perspective because it influences the quality of life in an organization, while from the 
company's point of view, it affects different job related aspects, e.g. work commitment, job satisfaction or intention to stay. The images of person-organization fit presented in the paper connect two important variables: organization formalization and employees' certainty orientation. As the consequences of lack of personorganization fit can be significant, the presented images can help to understand the meaning of the analyzed relationship. As G. Morgan underlines, images or metaphors persuade managers and researchers to see, understand and imagine situations in partial ways (Morgan, 2006). Different metaphors have a capacity to tap different dimensions of situation.

The images presented in this paper help to understand and predict employees, coworkers and managers' behavior, feelings, reactions and expectations in the perspective of person-organization fit. One should also remember that although images and metaphors are very helpful in exploring and understanding organizational life, to some extend they can be limiting and blocking other perception of existing situation. The theoretical model presented in the paper may be a starting point for future research. As the model seems to be universal for different national cultures it can be implemented to compare differences and build national types of personorganization fit.

\section{References}

Arbour, S., Kwantes, C.T., Kraft J.M. \& Boglarsky, Ch.A. (2014). Personorganization fit: using normative behaviors to predict workplace satisfaction, stress and intentions to stay, Journal of Organizational Culture, Communications and Conflict, 18(1), 41-65.

Becker, G.S. (1975). Human Capital: A Theoretical and Empirical Analysis $\left(2^{\text {nd }}\right.$ ed.), New York, National Bureau of Economic Research.

Bielski, M. (1992). Organizacje. Istota, struktury, procesy, Lodz, Wyd. Uniwersytetu Lodzkiego.

Bowers, K. S. (1973). Situationism in psychology. Analysis and a critique. Psychological Review, 80(5), 307-336.

Chan, W., Mauborgne, R. (2006). Chcesz, by pracownicy dali z siebie wszystko? Graj fair!, Harvard Business Review Polska, 42(8), 128-134. 
Crozier, M. (2010). The Bureaucratic Phenomenon. New Brunswick and London: Transactions Publishers. Originally published: Chicago: University of Chicago Press, 1964.

Czarnecki, J. (2011) Architektura korporacji. Analiza teoretyczna i metodologiczna, Lodz, Wydawnictwo Uniwersytetu Lodzkiego.

Edwards, J.R. (1996). An examination of competing versions of person-environment fit approach, Academy of Management Journal, 39, 292-339, doi: $10.2307 / 256782$

Guan, Y., Deng, H., Risavy, S. D. Bond, M.H. \& Li, F. (2011). Supplementary Fit, Complementary Fit, and Work-Related Outcomes: The Role of SelfConstrual, Applied Psychology: An International Review, 60 (2), 286-310

Han, T.S., Chiang, H.H., McConville, D., Chiang, C.L. (2015). A longitudinal investigation of person-organization fit, person-job fit, and contextual performance: The mediating role of psychological ownership, Human Performance, 28 (5), 425-439 doi:10.1080/08959285.2015.1021048

Handy, Ch. (2002). The Age of Unreason. London: Random House Group Ltd.

Jansen, K.J., Kristof-Brown, A. (2006). Toward multidimensional theory of personenvironment fit, Journal of Managerial Issues, 18 (2), 193-212.

Kihlstrom, J.F. (2013). The person-situation interaction. In D. E. Carlston (ED.). The Oxford Handbook of Social Cognition, Oxford Library of Psychology.

Kozminski, A.K. \& Piotrowski, W. (1995). Zarzadzanie. Teoria i praktyka, Warszawa, Wydawnictwo PWN.

Kristof, A. (1996). Person-organization fit: An integrative review of its conceptualizations, Measurement, and Implications, Personnel Psychology, 49(1), 1-49, doi: 10.1111/j.1744-6570.1996.tb01790.x

Kristof-Brown, A.L., Zimmerman, R.D. \& Johnson, E.C. (2005). Consequences of individuals' fit at work: A meta-analysis of person-job, person-organization, person-group, and person-supervisor fit, Personnel Psychology, 58 (2), 281342, doi: 10.1111/j.1744-6570.2005.00672.x

Laloux F. (2014). Reinventing Organizations: A Guide to Creating Organizations Inspired by the Next Stage of Human Consciousness. Brussel, Nelson Parker. 
Lewin, K. (1946/1951). Behavior and development as a function of the total situation. In K. Lewin (Ed.), Field theory in social science. New York: Harper \& Ro.

Morgan, G. (2006), Images of Organization, California, Updated edition, Sage Publication.

Muchinsky, P.M. \&. Monahan, C.J., (1987). What is person-environment congruence? Supplementary versus complementary models of fit, Journal of Vocational Behavior, 31 (3), 268-277.

Oh, I.S., Guay, R.P., Kim, K., Harold, C.M., Lee, J.H., Heo, C.G., Shin, K.H. (2014). Fit happens globally: A meta-analytic comparison of the relationships of person-environment fit dimensions with work attitudes and performance across East Asia, Europe, and North America, Personnel Psychology, 67(1), 99-152, doi: 10.1111/peps. 12026

Rai, G.S. (1983). Reducing bureaucratic inflexibility. Social Service Review, 57 (1), 44-58.

Roney, C. J. R., \& Sorrentino, R. M. (1995). Reducing self-discrepancies or maintaining selfcongruence? Uncertainty orientation, self - regulation, and performance. Journal of Personality and Social Psychology, 68 (3), 485-497, doi: org/10.1037/0022-3514.68.3.485.

Seong, J.Y. (2016). Person-organization fit, family-supportive organization perceptions, and self-efficacy affect work-life balance, Social Behavior and Personality, 44(6), 911-921

Sorrentino, R. M., \& Roney, C. R. J. (2000). The Uncertain Mind: Individual Differences in Facing the Unknown. Psychology Press: Philadelphia, PA.

Sorrentino, R. M., Hanna, S. E. Holmes, J.G., Sharp, A. (1995). Uncertainty Orientation and Trust in Close Relationships: Individual Differences in Cognitive Styles, Journal of Personality \& Social Psychology, 68 (2), 314 327, doi: 10.1037/0022-3514.68.2.314

Sorrentino, R.M., Ye, Yang, \& Szeto, A. C. (2009). Uncertainty Management: To Fear or Not to Fear? Psychological Inquiry, 20(4), 240-244, doi: $10.1080 / 10478400903333528$.

Swiatek-Barylska I. (2013). Lojalnosc pracowników współczesnych organizacji, Istota i elementy składowe, Lodz, Wyd. Uniwersytetu Lodzkiego. 
Swider, B.W., Zimmerman, R.D. \& Barrick, M.R. (2015). Searching for the right fit: Development of applicant person-organization fit perceptions during the recruitment process, Journal of Applied Psychology, 100 (3), 880-893.

Szeto, A.C., Sorrentino, R.M., Otsubo Y., Nezlek, J. Uncertainty Orientation: A Theory of Self-Regulation within and Across Cultures as Related to Cognition. Retrieved from http://www.iaccp.org (accessed: May 15, 2016).

Toffler, A. (1980). Third Wave. New York, Bantam Books.

Wellin, M. (2007). Managing the Psychological Contract. Using the Personal Deal to Increase Business Performance. New York, Routledge.

Westerman, J.W., Cyr, L.A. (2004). An Integrative Analysis of Person-Organization Fit Theories. International Journal of Selection and Assessment, 12(3), 252261. 